\title{
eCOti
DiAno
}

Revista Mídia e Cotidiano

ISSN: 2178-602X

Artigo Seção Temática

Volume 14, Número 2, maio-ago. de 2020

Submetido em: 27/11/2019

Aprovado em: 06/02/2020

\section{O desenvolvimento da escrita feminina na imprensa da Paraíba: um olhar para a crônica e para a história das mullheres}

\section{The development of female writing in the state of Paraiba's press: a look at women's chronicle and history}

\author{
Maryellen BÃDÃRÃ $U^{1}$ \\ Sandra Raquew AZEVÊDO ${ }^{2}$
}

\section{Resumo}

Como parte de uma dissertação que abordou o estudo da crônica feminina no jornalismo paraibano, este artigo tem como objetivo introduzir a temática da escrita feminina na imprensa local. Foi neste espaço público que as mulheres passaram a narrar o seu cotidiano e a debater sobre sua condição de desigualdade, transformando estes escritos em um retrato histórico, político e social da experiência feminina. Dessa forma, visualizamos a crescente entrada das mulheres na imprensa ao longo dos séculos, culminando nos dias atuais em uma participação plural e especializada. Para entendermos como este fenômeno se deu no cenário paraibano, analisamos primordialmente como a escrita foi importante para o estabelecimento do discurso feminino e sua entrada permanente neste "lugar de fala". A partir disso, debatemos o papel da escrita, nesse caso da crônica, na consolidação desse "lugar social" e representação das mulheres, além de perceber como esta prática mantém uma relação intrínseca com o cotidiano feminino, revelando as trajetórias de vida na imprensa.

Palavras-chave: Gênero. Escrita feminina. Imprensa. Cotidiano. Jornalismo paraibano.

\begin{abstract}
As part of a dissertation that addressed the study of female chronicles in the state of Paraíba's journalism, this article aims to introduce the theme of female writing in the local press. Women started to narrate their daily lives and debate about their inequality conditions in this public space, transforming these writings into a historical, political and social portrait of female experience. In this way, we visualize the growing participation of women in the press over the centuries, which takes us to the present day's plural and specialized participation. In order to understand how this phenomenon took place in the

\footnotetext{
1 Mestra em Comunicação pelo Programa de Pós-graduação em Comunicação (UFPB). E-mail: maryellen_ingrid@hotmail.com. ORCID: 0000-0002-0491-8375.

2 Professora Associada do Departamento de Jornalismo (UFPB) e Programa de Pós-graduação em Comunicação (UFPB). Doutora em Sociologia (UFPB). E-mail: criticadasmidias@ gmail.com. ORCID: 0000-0003-4475-0092.
} 
Paraíba scenario, we analyzed primarily how writing was important for the establishment of female discourse and its permanent presence in this "locus of enunciation". Finally, we debate the role of writing, and, specifically, the role of the chronicle for the consolidation of this "social place" and the representation of women. Additionally, we address the ways in which this practice maintains an intrinsic relationship with the daily life of women, revealing their life trajectories in the press.

Keywords: Gender; Female writing; Press; Daily; Paraiba journalism.

\section{Introdução}

A inserção da mulher na imprensa pode ser considerada um capítulo na história do jornalismo brasileiro que, além de transformar suas feições (sendo esta uma prática de hegemonia masculina), aos poucos também modificou a lógica social da presença feminina no espaço público. A possibilidade de acesso à educação desempenhou importante papel nesse processo. As publicações das mulheres, a princípio, refletiram as inquietações e os questionamentos relacionados à sua condição social no âmbito particular. Seus textos inscreveram a sua história pessoal dentro de um determinado espaço e tempo, mostrando sua trajetória e experiência de mundo no contexto de lutas e vivências.

Enquanto narradoras de suas próprias histórias, as mulheres passaram a publicar nos jornais e compartilhar suas questões para o público, mesmo que no início isso tenha acontecido de forma inibida, com pseudônimos. Esse ambiente fortaleceu, com o tempo, os discursos nos diferentes âmbitos de representação do cotidiano. Os estudos de gênero, mídia e escrita feminina, que posteriormente ganharam força a partir da organização e da atuação das mulheres em uma imprensa feminista, possibilitaram a elucidação dessa participação massiva na construção de narrativas nos jornais. É justamente a partir desse campo de pesquisa que estudamos a crônica feminina na imprensa paraibana, especificamente as escritoras atuantes nas páginas de opinião dos principais jornais impressos da Paraíba no século XXI, entre os anos de 2011 a 2017.

Dessa forma, esta pesquisa teve como objetivo entender como este cenário foi construído e quem são as escritoras da atualidade da imprensa paraibana. Além disso, visibilizamos as escritoras do passado, como uma forma de reconhecimento pela importância do trabalho que desempenharam. A escrita se tornou uma prática relevante 
importante para o fortalecimento do discurso feminino nas páginas dos jornais, configurando-se como um "lugar", conquistado através da organização e da luta das mulheres.

Através de uma pesquisa bibliográfica e documental, de caráter exploratória e descritiva, o nosso campo de estudo foi se desenvolvendo em uma linha do tempo, a partir dessa produção de sentidos, que vem materializando a história das mulheres desde o século XIX. Assim, pode-se ter uma noção das diversas visões e realidades cotidianas da "experiência feminina" nos muitos âmbitos sociais (MATOS, 2013). Nesse caso específico, na memória que a crônica produz sobre um determinado espaço e tempo.

Observamos poucos estudos voltados a traçar um cenário da escrita feminina no jornalismo paraibano no século XXI, por isso, buscamos manualmente nos jornais o nome das mulheres escritoras/jornalistas para traçar uma cartografia dessa presença nas páginas de opinião, no período de 2011 a 2017. Consideramos para este estudo mulheres jornalistas e escritoras (professoras e outras profissões) que, entre o período da pesquisa exploratória, configuraram uma presença permanente, por seis meses ou mais, nos jornais extintos O Contraponto, Jornal da Paraíba, O Norte e nos jornais Correio da Paraíba, A União e em seu complemento literário, o Correio das Artes. Através dos arquivos, chegamos na seguinte tabela: 


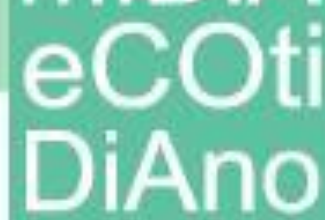

Tabela 1 - Quadro de escritoras/jornalistas paraibanas identificadas entre os anos de 2011 a 2017

\begin{tabular}{ccc}
\hline Jornalistas e Escritoras & Jornal & $\begin{array}{c}\text { Gênero Textual - } \\
\text { Jornalístico }\end{array}$ \\
\hline Ana Adelaide Peixoto & O Norte, Correio das Artes, O & Crônica \\
Ângela Bezerra de Castro & Contraponto & Correio das Artes \\
Elizabeth Marinheiro & Jornal da Paraíba & Crítica literária, Crônica \\
Joana Belarmino & Crítica literária \\
Katarine Laroche & O Contraponto A União, Correio das Artes & Crônica, Conto \\
Lena Guimarães & Correio da Paraíba & Crítica de Arte \\
Lourdinha Luna & A União, Correio da Paraíba & Artigo (Colunista) \\
Luciellen Souza & A União & Crônica \\
Molina Ribeiro & A União, Correio da Paraíba & Artigo \\
Neide Medeiros & O Contraponto & Crônica, Artigo literária, Poesia \\
Sandra Moura & A União & Artigo \\
Sony Lacerda & Correio da Paraíba & Artigo (Colunista) \\
Vitória Lima & A União & Crônica, Crítica literária \\
\hline
\end{tabular}

Fonte: Elaborado pela autora (2017).

A partir das observações de Barbosa Filho (2018), outras mulheres apareceram nesse cenário da imprensa paraibana, além das que elencamos na tabela: Belminda Vinagre, Mariana Cantalice Soares, Maria das Graças Santiago, Claudia Gondim e Clotilde Tavares. Nessa compreensão, elencamos para a pesquisa as escritoras que configuram permanentemente a crônica feminina na imprensa paraibana (destacadas no quadro) considerando que este gênero é a escrita que mais evidencia o cotidiano das mulheres no cenário local. Entre elas, as professoras Ana Adelaide Peixoto e Vitória Lima, e a jornalista e professora Joana Belarmino, desde a juventude, destacaram-se com narrativas e representações do feminino em livros e jornais. São mulheres com alto grau de conhecimento, acadêmicas e que ocupam espaços semelhantes na sociedade, nos âmbitos culturais, artísticos, políticos e econômicos.

A escolha da crônica como objeto de análise se deu por sua relevância no campo de atuação da escrita das mulheres no jornalismo local, o que nos possibilitou mais aporte e material para o estudo. O recorte temporal escolhido tem em comum a atividade de todos 
os principais jornais de João Pessoa, já que, precisaríamos, a princípio, classificar as mulheres atuantes nas páginas de opinião e os gêneros textuais habitualmente encontrados em suas publicações. Depois disso, avaliar quais mulheres e categoriais se destacariam e confirmar a pertinência da escolha da crônica como um gênero maior na representação do cotidiano.

Mencionamos ainda que a escolha dos jornais se deu puramente pelo interesse exploratório, pois não poderíamos descartar qualquer possibilidade de atuação relevante de mulheres que apareceriam apenas em um único periódico. Destacamos também que, para esta pesquisa, não levamos em conta o caráter editorial/histórico dos jornais, tendo em vista nosso foco na escrita e nas escritoras, não tendo elas nenhum vínculo profissional com as empresas por trás dos periódicos. Sua escrita nesses jornais tem relação exclusivamente voluntária, que, nesse cenário local, se faz comum nas páginas de opinião, tanto para homens quanto para mulheres.

Mesmo assim, não desconsideramos a importância da relação tênue entre jornalismo e literatura, através da crônica, e sua contribuição para o desenvolvimento de um espaço propício para a proclamação de tantas vozes, com variadas perspectivas de um mesmo cotidiano. Este gênero se tornou ferramenta que possibilitou a inscrição de novos enunciados sobre o feminino e o seu percurso histórico, tanto na literatura quanto no jornalismo. Graças à sua flexibilidade narrativa em relação à linguagem técnica do jornalismo impresso e o rigor literário, destacou-se pelas possibilidades de organização dos enunciados, deixando de lado o rigor cronológico e "linguagem neutra" e impessoal.

Apesar de ser originária do jornal, a crônica não acompanha as formas temporais e espaciais estabelecidas, sendo definida como um gênero textual que se alimenta do instante, do momento e se constrói em sua própria rotina, ora seguindo o ritmo da atualidade jornalística, ora acompanhando apenas o seu próprio tempo narrativo. A partir do sujeito que a escreve, representa sua visão particular dos fatos que, através dela, levanta questões pertinentes e constrói um leque de discussões no âmbito social.

Para contextualizarmos este lugar ocupado pelas escritoras, questionamos a presença feminina na imprensa paraibana, problematizando a visibilidade da atuação dessas mulheres, que compõem um espaço importante e especializado do jornalismo local. Também refletimos o papel da escrita no processo de representação do cotidiano, 


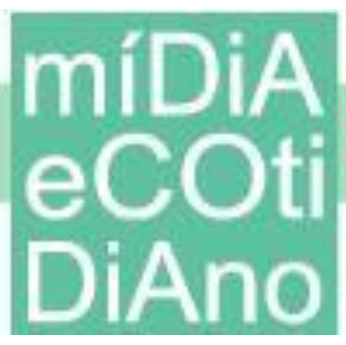

que se constitui como uma prática social importantíssima no campo de atuação feminino. Os escritos encontrados traduzem diversos temas que abordam literatura, política, viagens, reflexões sobre o cotidiano da cidade e suas experiências intrínsecas como mulheres, tendo uma periodicidade de publicação semanal.

\section{A escrita como um lugar de fala e representação}

Segundo Pinheiro (2010), o século XIX foi marcado pela inserção da mulher na imprensa que, a partir de uma visão masculina, começou a ser representada em revistas e periódicos, criados especialmente para entreter o público feminino. Essas produções enfatizavam o discurso patriarcal onde a mulher ideal era a que mantivesse sua atenção voltada ao lar, tecnicamente ao âmbito privado. Os jornais eram pensados para orientar as mulheres em suas diversas atividades domésticas (corte e costura, beleza, saúde, casamento e maternidade), focando principalmente em atender as expectativas sociais em relação a imagem da mulher do lar, que na época era tido como padrão. Esse modelo se consolidou na sociedade, desenvolvendo cadernos para mulheres casadas e solteiras, e segmentando as páginas para os públicos a partir do conteúdo que seria abordado.

No entanto, isso foi modificado no século XX, graças à mobilização das mulheres, que se organizaram para lutar pelo seu ingresso nos espaços públicos. A autoria feminina nos jornais na década de 1930 já era identificada, apesar da pouca visibilidade. Entre os anos 1960-1970 grupos de mulheres fundaram jornais e revistas, como resultado da articulação política e social e em resposta às opressões vividas. Os periódicos criados serviram para discutir as questões urgentes do seu cotidiano, no que se refere ao âmbito dos direitos por uma equidade de gênero. Logo, essa parcela de mulheres se reuniu para inserir na imprensa textos que iam contra o ideal da época e que incentivavam o desenvolvimento de "um novo regime discursivo", que valorizassem a mulher e garantisse os seus direitos e um lugar de fala e representação, conforme afirma Teles e Leite (2013, p. 14).

Enquanto a "imprensa feminina", a partir do crivo masculino, representava a mulher "do lar", a imprensa feminista vinha a ser um contraponto, democratizando as visões e representações das mulheres nos periódicos. A partir das produções de jornais e revistas alternativas no século $\mathrm{XX}$, a imprensa foi um canal usado para disseminar a história da luta das mulheres da época. Seus escritos enfrentaram censura e críticas, tendo 


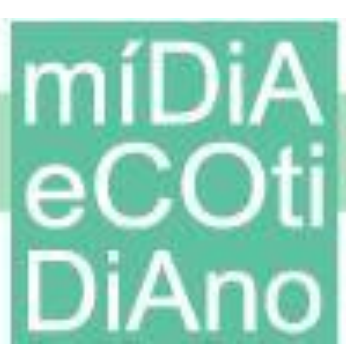

a necessidade do uso de pseudônimos no início do movimento, para que as produções fossem publicadas e mais aceitas socialmente.

Desse cenário, podemos compreender o envolvimento das mulheres em constituir uma imprensa pautada na opinião, com um caráter ideológico que aborda seu cotidiano, a partir do entendimento de que uma imprensa feminina as representava em uma referencialidade temporal que as distanciava de um jornalismo informativo (BUITONI, 1981). A representação das mulheres através da visão masculina, além de afastar a imprensa feminina da atualidade, fez com que, por muitos anos, acredita Buitoni (1986), as mulheres fossem consideradas um "mito" na imprensa.

Decerto, o trabalho das mulheres na imprensa, desde sua inserção no século XIX, contribuiu para a discussão sobre o seu papel na sociedade e para que a trajetória feminina fosse escrita na história. Devido a esse "lugar da mulher" estar relacionado ao âmbito privado, pouco se sabia historicamente sobre suas experiências e pertinências. As produções textuais publicadas em uma imprensa que repensava o feminino, oportunizaram o direito ao registro da jornada das mulheres no espaço público.

Assim como em todo o país, na Paraíba as mulheres seguiram este caminho. Primeiro, veio a concessão ao direito à educação em 1827, a partir da regulamentação ${ }^{3}$ das "Escolas de Primeiras Letras" no Brasil, que abriu as portas para o contato das mulheres com as letras e, consequentemente, com a literatura. Segundo Nascimento (2013), a formação gerou "um senso crítico, lógico e artístico" e isso foi essencial para modificar o papel da mulher na sociedade, transformando a realidade à sua volta. Depois, o interesse em discutir as pertinências em seu cotidiano, questionando sua condição ainda inferior em relação aos homens e relatando suas experiências diárias.

Acredita-se que essa tendência de silenciamento feminino retirou as mulheres de "cena", apagando muitas trajetórias na história oficial da escrita. As "mulheres de letras" existiram e atuaram no jornalismo paraibano, mas isso só veio a ser redescoberto a partir de pesquisas de gênero e escrita feminina no Brasil, sobretudo nas últimas décadas. Nunes

\footnotetext{
${ }^{3}$ Segundo a Legislação de 15 de outubro de 1827, disponível em https://bit.ly/2XuoBRv. Acesso em: 23 maio 2020.
} 
(2013) confirma a premissa, quando mostra os resultados de sua pesquisa em que apenas $1 \%$ dos escritos, estudados na década de 1930, constavam como produzidos por mulheres.

Outro trabalho que discute a atuação das mulheres na escrita paraibana é o estudo de Bernardo (2013), que analisou os registros das professoras e escritoras do século XX e revela justamente a mesma ausência das mulheres nos jornais e na literatura. Ela considera que esses resultados são a prova de que esse silêncio aconteceu e afetou a inserção de vozes femininas ativas na descrição dos acontecimentos da história oficial ou do discurso científico.

Assim, em um primeiro momento, a escrita se torna um degrau que a mulher sobe em direção à esfera pública. A partir dessa prática, puderam externar seus pensamentos, suas experiências e seu cotidiano, o que lhes abriu portas, tendo em vista que a escrita transforma a percepção do mundo e a percepção de si mesmas. A partir do andamento desse processo crítico dos acontecimentos, a mulher questionou a realidade à sua volta, mediante o reconhecimento de outras mulheres escritoras. Aos poucos, adentraram na imprensa e seus escritos se tornaram ferramenta importante para uma elucidação coletiva do feminino no âmbito social.

Magalhães e Alvarez (2014) levam em consideração a entrada definitiva da mulher na imprensa como ponto crucial para o desenvolvimento do jornal, o que trouxe mudanças para o cenário que já estava bastante modificado, tanto em relação ao seu modus operandi quanto às definições ideológicas, praticadas nos meios de comunicação de massa. Sendo assim, o ingresso e a participação da mulher na imprensa podem ser considerados uma renovação na comunicação, que faz parte de um processo social, político e econômico, que não se deu de forma espontânea (MAGALHÃES; ALVAREZ, 2014, p. 11).

Podemos afirmar, então, que a escrita se torna "um lugar de legitimação e de domínio”, segundo Tedeschi (2016, p. 154), principalmente quando damos atenção ao processo de escrita da história. Os homens que detinham o letramento - geralmente os escritores e historiadores - puderam explorar, de maneira hegemônica, o uso dos símbolos e das representações para legitimar o seu discurso diante de suas narrativas. Mas, depois, as mulheres tomaram esse espaço trazendo um novo olhar e um conjunto de problematizações para essa prática, modificando a lógica de dominação e transcendendo o silenciamento feminino. 
Durante muito tempo, a escrita e o saber estiveram - e ainda, talvez, continuem - relacionados ao poder e foram usados como formas de dominação e de exclusão de determinadas vozes que tentaram ecoar algum som em meio ao silêncio que era imposto para que se mantivesse a ordem social em uma sociedade de base falocêntrica, patriarcal, machista e sexista. Mesmo assim, o discurso hegemônico do patriarcalismo não conseguiu abafar determinadas vozes, principalmente de algumas mulheres insatisfeitas com o rótulo de o "segundo sexo" e que, por isso, não se submeteram à subordinação. Por causa, dentre outros fatores, das tentativas de subversão à ordem do pai, a integração de mulheres/escritoras no universo da escrita foi marcada por uma trajetória bastante dolorosa (TEDESCHI, 2016, p. 155).

Dessa forma, podemos considerar que a escrita, e a crônica, se tornam um lugar (CERTEAU, 1982, p. 17), onde os discursos se estabelecem e se transformam ao longo do tempo, simbolizando que, quem a detém, é capaz de modificar seu ambiente em função de um desejo pela mudança, pelo saber e pelo dominar. São ferramentas para "instauração de campos próprios" de novos cenários e significados. Quando as mulheres tomam posse dessa prática e a consolidam, passam a existir nesse "lugar".

Simbolicamente, as mulheres perpassaram esses discursos dominantes, fazendo da sua própria produção de sentidos um "fazer pelo dizer", quebrando o silenciamento histórico e invertendo a ordem estabelecida, onde os discursos dependem de sua própria interpretação, em uma visão específica dos acontecimentos. Transformam também a práxis social, que agora destaca o sujeito feminino e a sua posição no "lugar" histórico, em detrimento dos discursos que pairam no passado, conectando o "ato produtor" e o “objeto produzido" em uma única e exclusiva prática, sendo as mulheres sua "testemunha frágil”, mas também sua própria “crítica necessária” (CERTEAU, 1982).

Essa construção do real gera uma nova interpretação sobre o cotidiano e sobre as demandas de gênero levantadas nos textos das mulheres, oportunizando a incorporação de novos conceitos a serem creditados socialmente. As transformações passaram a acontecer a partir da organização de ações sociais, que traduzem uma busca por uma voz e um objetivo em comum: uma representação feminina positiva, que possibilite melhorias em todos os setores onde a mulher se encontra em desigualdade.

A dinâmica e a diversidade desse pensamento social coletivo nos remetem ao conceito da Teoria das Representações Sociais, apresentado por Arruda (2002), que esclarece como essa organização de códigos se dá dentro de uma estrutura científica e 


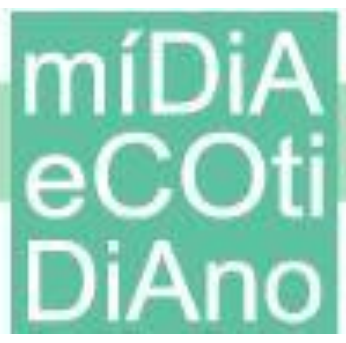

consensual de produção de sentidos. Essa prática está inserida em uma linguagem científica, mas também habita no senso comum, quebrando paradigmas em favor de novos entendimentos para as questões de gênero.

No contexto paraibano, as mulheres usaram a escrita, a partir desse cenário constituído pela relação de literatura e do jornalismo através da crônica, para pluralizar as visões sobre os acontecimentos. Dessa forma, consolidaram-se como protagonistas de suas próprias histórias, narrando com seus códigos e linguagens os contextos que estão circunscritas e vendo, através desse trabalho, resultados que elevam e consolidam a atuação e representação do feminino nos espaços públicos. Esse olhar, que parte de uma perspectiva subjetiva, tem conexão com sua condição social e nos revela uma abertura crítica, baseada em experiências que, por questões de desigualdade de gênero, se tornam totalmente diferente da dos homens.

É justamente nesse contexto que se encontra a pertinência, entre outras muitas razões, da importância dessa pluralidade, que expõe uma "cultura específica" relacionada a um "saber local" e localiza a ação feminina dentro de um contexto de discursos dominantes na imprensa paraibana. Essa prática social é perpassada por categorias subjetivas, através dos filtros próprios, da experiência de vida e da percepção de mundo. Dessa forma, a escrita feminina, neste caso a partir da crônica, passa a ser considerada um discurso do "senso comum" e posteriormente, como fonte de um saber, que reconfigura as formas de olhar para o mundo.

\section{O desenvolvimento da imprensa feminina na Paraíba}

De acordo com Souza (2011), a imprensa paraibana do século XIX foi constituída, em sua maioria, por uma elite intelectual que valorava a instrução e a usava como técnica para produção de textos culturais e políticos. Era uma imprensa que focava na disseminação de textos a respeito de diversos temas: política, leis, literatura e sociedade, de um modo geral. Essa instrução, diz o autor, foi responsável por trazer uma “civilização" cultural na imprensa, tornando-a difusora desses discursos.

Os agentes inseridos nesse contexto eram estudiosos, médicos, advogados, jornalistas, políticos e professores, personagens diretamente ligados a uma formação intelectual e cultural, características que ressaltam, de forma muito clara, nos textos que 


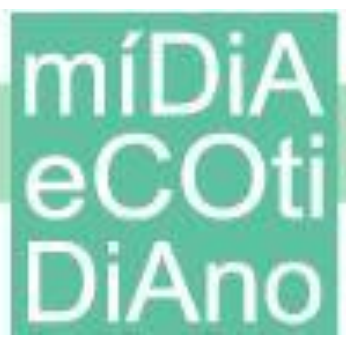

eram produzidos. Essa prática se pautava em um contexto político-social da época, que fomentava um discurso partidário vivenciado pela sociedade local.

Os textos "opinativos" apresentados nos jornais do fim do século XIX seguiam seu "caráter didático", englobando fatos, poesia, política e ciências, que até a década de 1970 se apresentavam em uma página intitulada "literária", apresentando os diversos gêneros comumente publicados na imprensa paraibana, entre eles ensaios, cartas, resenhas, biografias, poemas, contos e crônicas (VILAR, 2005, p. 3). Os conteúdos publicados não apresentavam autoria ou eram divulgados a partir de pseudônimos, o que pode indicar a participação feminina na imprensa.

Por enfrentar resistências relacionadas à atuação no âmbito público, as mulheres passaram a escrever na imprensa para manifestar sua insatisfação e lutar por seus direitos, como votar, trabalhar, divorciar-se. A escrita, nesse caso, foi a ferramenta que possibilitou às mulheres romperem as barreiras em busca da quebra do "silêncio". A educação está diretamente relacionada com esse movimento de emancipação feminina na Paraíba, que propiciou às mulheres o acesso ao trabalho fora do âmbito privado, geralmente vinculado ao Magistério, mas também ao Direito, à Medicina e outras profissões prestigiadas socialmente (PAIVA; DUARTE, 2009).

A pesquisa de Bernardo (2013) revelou a participação de mulheres, que datam do final do século XIX e início do XX, que são elas: Anayde Beiriz, Analice Caldas Barros, Eudésia Vieira, Lylia Guedes, Olívia Carneiro da Cunha. Outras escritoras foram identificadas pela pesquisadora posteriormente, como Apolônia Amorim, Ambrosina Magalhães, Albertina Correia Lima, Alice Azevedo Monteiro, Catarina Moura, Francisca Rodrigues Chaves Moura, Francisca de Ascenção Cunha, Isabel Iracema Feijó da Silveira, Iracema Marinho e Juanita Machado.

No Pequeno Dicionário dos Escritores/Jornalistas da Paraíba do século XIX (2009), pudemos detectar outras mulheres atuantes na imprensa paraibana desse século, tais quais Ezilda Milanez, Leonarda Merandolina e Beatriz Ribeiro. A pesquisadora Maria Lúcia Nunes (2016) também desenvolveu um projeto relacionado aos estudos dos escritos femininos nos jornais paraibanos entre os anos de 1920 a 1930, que contribuiu para evidenciar a presença de outras mulheres e menciona Olivina Olívia, Julita Ribeiro, 


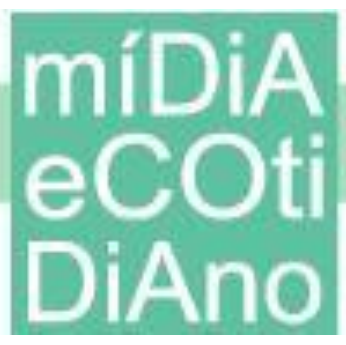

Tercia Bonavides, Carmita Coelho, Angelina Pereira Gomes e Dalva Santiago Rangel como escritoras precursoras dessa cena local.

As escritoras pioneiras seguiram uma direção contrária da história, sendo "desobedientes" à sociedade, que considerava um "escândalo" o fato de a mulher ler, escrever, trabalhar fora do âmbito familiar, opinar e publicar textos, sendo "expostas". A partir destas práticas, de maneira muito intuitiva e consistente, as escritoras foram rompendo o silêncio e conquistando um lugar no espaço público, seja ele na literatura e/ou na imprensa. Através da sua escrita, relata Sales (2005), estas mulheres socializaram “outras possibilidades para o Ser Mulher”, destacando suas lutas políticas em um cenário de preconceitos. Assim, as escritoras paraibanas, teceram, a partir do ato de educar e escrever, um cotidiano de resistências, construindo uma luta política e novas possibilidades de atuação para o público feminino.

O período precursor da história da imprensa e da literatura feminina paraibana foi marcado pelas particularidades de cada escrita, evidenciando um contexto social e o lugar das autoras. O que tinham em comum era um "fio condutor", segundo Sales (2005), que fazia referência à interlocução feminina, relacionada à opressão social.

Algumas décadas após este marco, em um contexto pós-luta armada, que se refere à ditadura militar (1964-1985), as mulheres passaram a se organizar de forma mais incisiva e o movimento feminista obtém um crescimento consistente na imprensa. Um evento importante deste movimento foi a reunião na Associação Brasileira de Imprensa (ABI), com apoio da Organização das Nações Unidas (ONU), que resultou na criação do Centro da Mulher Brasileira (TELES; LEITE, 2013, p. 52).

A partir de 1975, o grupo de mulheres fundou o Brasil Mulher (1975-1980) e o Nós Mulheres (1976-1978), para garantir mais espaço nos campos de disputa, na imprensa e no social. Esses jornais foram de mais destaque durante a Ditadura Militar, segundo o estudo sobre a construção do feminismo na imprensa. Isso teve impacto em organizações feministas de todo o país, e reafirma a trajetória histórica e política do movimento no século $\mathrm{XX}$, a partir da retomada pública do movimento feminista no Brasil e da explanação das lutas sociais de mulheres de diferentes realidades, dentro do mesmo contexto histórico.

No século XXI, a escrita feminina ainda se mantém forte no jornalismo paraibano, caracterizado majoritariamente por mulheres de alta instrução, seguindo as 
características iniciais do surgimento da imprensa paraibana. Estas destacam opiniões e pontos de vistas particulares, compromissadas com o dia a dia, narrando os acontecimentos de forma perspicaz, a depender do estilo de cada escritora. Seus escritos aparecem geralmente nas páginas de opinião dos jornais, mas podem estar fixadas em outras páginas e cadernos, mantendo uma consistência em suas publicações, que são reveladas periodicamente a cada semana.

Na Paraíba, o contexto da escrita feminina está mantido em uma produção majoritariamente opinativa, que, considerando a trajetória dessas mulheres no jornalismo local, pode-se afirmar que essa presença feminina é, antes de tudo, uma manifestação política de autonomia que, com muitas barreiras sociais, conseguiu avançar e conquistar espaços de poder e representação. Figueiras (2011) reflete sobre esse processo:

Mulheres e homens não partilham as mesmas hipóteses no acesso a posições de topo e exercício de poder. Quanto mais subimos na escala hierárquica, menor é a probabilidade de encontrarmos mulheres. Por outro lado, o acesso aos media e o perfil dos atores com protagonismo midiático, nomeadamente no espaço de comentário, são um reflexo da estrutura de poder social, econômico, político e cultural da sociedade onde se inserem (FIGUEIRAS, 2011, p. 81).

Essa presença feminina na imprensa constitui o acervo importante que conta toda a mobilização das "mulheres das letras" no jornalismo da Paraíba, e narram os acontecimentos dando sentido a suas próprias representações. Além disso, o jornal como espaço de visibilidade se torna o seu lugar de significação dos fatos do cotidiano, a partir do posicionamento dos agentes sociais, que, individualmente, reproduzem o seu próprio imaginário, buscando comentar e interpretar o mundo à sua volta.

A crônica é o gênero jornalístico que mais se destaca nesta inscrição, com uma importante descrição histórica, lírica e poética dos acontecimentos, tanto no âmbito feminino, quanto no cotidiano. Entre as mulheres em destaque, estudamos com mais afinco a atuação das cronistas Ana Adelaide Peixoto, Joana Belarmino e Vitória Lima, como os nomes de força que representam a escrita feminina atualmente. O trabalho delas não se restringe apenas à imprensa, que usam como ferramenta de fomento à literatura local, compondo um vasto campo literário, que tem seu cenário plural, democrático e especializado. 
Segundo enfatiza Hildeberto Barbosa Filho ${ }^{4}$, a imprensa paraibana, desde do século XX, concede grande abertura para a literatura e a cultura, de modo geral. Mesmo que os espaços para veiculação de textos literários, inclusive das crônicas, tenham diminuído ao longo dos séculos, tendo que "competir" com o fluxo de informações constantemente, a veiculação desses escritos em espaços especializados se tornou uma realidade na Paraíba. Um exemplo disso é a formulação do Correio das Artes, antes um caderno especial tipicamente literário, que era publicado mensalmente pelo jornal A União; atualmente, se consolidou-se como um suplemento literário do periódico.

A crônica ganha um espaço importante nesta configuração. Além do destaque neste espaço página e sua relevante relação com o tempo, já que etimologicamente vem do latim chronica e do grego khronos, tem ligação com o registro do cotidiano e da trajetória das mulheres. Mas, pela sua hibridez, transpõe os limites espaciais e técnicos pré-estabelecidos nos jornais e alcança sua independência como mecanismo discursivo. Dessa forma, a crônica passa não somente a descrever os fatos do cotidiano nos jornais, como também a narrar a "temática do eu", dando a elacom uma perspectiva particular (GOTTARDI, 2007).

Estudos historiográficos vêm contribuindo, desde o seu início, para a elucidação pluralidade das visões em relação ao cotidiano das mulheres no passado e no presente. A partir de pesquisas em fontes oficiais, não oficiais e através da história oral, buscam evidenciar uma leitura crítica, fomentando a discussão sobre a participação feminina na sociedade. Apesar da fragmentação dos registros da atuação feminina, a crônica vem a ser uma dessas fontes, que possibilitou, e possibilita até os dias de hoje, a visualização de um espelho do passado, constituindo-se como um "lugar de memória" para as mulheres.

De acordo com Pereira (2010, p. 6), essa memória pode ser considerada uma "memória coletiva", tendo em vista que, mesmo narrado a partir de uma escritora, as temáticas debatidas representam a condição das lutas diárias das mulheres no âmbito social. A dimensão das escritas estudadas nos mostra que isso se dá devido às particularidades e às similaridades de cada escritora.

\footnotetext{
${ }^{4}$ Entrevistas em profundidade concedidas à autora (18 jun. 2018).
} 
É uma crônica que remete à uma memória afetiva, fazendo desse elemento um forte aliado na produção textual. $\mathrm{O}$ aspecto subjetivo dos textos se dá justamente nessa relação da atualidade com a memória, que remete a um passado, no qual as cronistas narram situações que, até então, ficavam no âmbito particular. Assim, conectam esse contexto com a temática a ser explorada.

Já as rotinas de escrita convergem para um momento muito similar entre as três cronistas, que separam um período da semana para vasculhar os acontecimentos na imprensa local e, a partir disso, escrevem os textos. Cada crônica tem um limite de 36 linhas, adequando-se aos limites espaciais dos jornais que ocupam. Apesar de ambas serem escritoras, produzir crônicas não é a sua atividade principal. Sua vivência com a imprensa, ao longo da vida, foi exercida ao passo que outras experiências, como a maternidade e a docência, foram acontecendo. Isso demonstra, na prática, que o processo de ingresso e a permanência das mulheres na imprensa ainda é difícil e desafiador.

A escolha das pautas depende do impacto diante o fluxo diário dos acontecimentos. O que se observa nas publicações é uma pluralidade da produção, que vem convergir, nessa análise, na semana do Dia Internacional da Mulher. As publicações envolvem reflexões sobre o feminino, a violência contra a mulher e as lutas sociais referentes ao tema. Por ser algo tão peculiar, cada crônica vai obter sua característica distinta, que converge com a história de vida das escritoras. Isso denota o desenvolvimento de uma identidade, capaz de pluralizar os olhares sobre o cotidiano na imprensa paraibana.

Dessa forma, podemos considerar que esse espaço em questão projeta a possibilidade de escritas de si, baseadas nesse compartilhamento de experiências ao longo da vida e que são publicadas na imprensa local. A pertinência dessa escrita para as mulheres consiste, justamente, nessa produção de sentido, de um saber historiográfico, alimentado e disseminado nas páginas dos jornais. Esse saber eleva não somente a escrita, mas também a vida das escritoras aqui mencionadas, configurando um discurso dominante de uma crônica feminina que é maior, plural e tem autoridade.

\section{Considerações}

No decorrer desta pesquisa, tive a satisfação de descobrir a história de muitas escritoras paraibanas, muitas vezes invisibilizadas na imprensa local, mas que 


\section{míDiA

desempenham importante papel dentro do cenário cultural, onde se tornam protagonistas de suas próprias trajetórias. Conhecer esse cenário de atuação tão vasto na Paraíba possibilitou o reconhecimento da inscrição de trajetórias de vidas importantes, para a compreensão de como a escrita feminina se fixa no jornalismo local.

As escritoras, nesse contexto, são muito mais do que interpretadoras do cotidiano, são atuantes em um mundo onde elas mesmas precisam ser interpretadas e compreendidas, não em um sentido de inferiorização dos discursos, como cita Arruda (2002), quando aborda sobre a objetificação do sujeito. Trata-se de pensar a formulação e concepção da escrita feminina na imprensa paraibana, a partir de uma autointerpretação das experiências de vida, dos sentimentos, de anseios e sonhos, que acabam por se tornar matéria prima para a criatividade na produção textual. Ou seja, para que compreendam o mundo, precisam compreender a si próprias.

Esse ponto de vista possibilitou destacar nomes de diversas mulheres, muitas vezes desconhecidas no meio jornalístico que, para a nossa surpresa, foram/são professoras, médicas, advogadas, literatas etc., participantes, desde o século XIX, de quando datam os primeiros registros. Assim como nesse período, atualmente a inscrição da história de mulheres escritoras ainda continua sem muita visibilidade, com poucas exceções.

A representatividade do feminino é, sem medidas, importante para a validação dessa escrita, onde mulheres no Brasil e na Paraíba se destacaram. A relevância dessa atividade, na concepção em que a pesquisa se situa, está justamente sobre os resultados dessa produção textual. Ao interpretarmos esta história escrita pelas mulheres, observamos as transformações e a articulação feminina no meio social. É disso que trata a escrita feminina abordada neste texto: de uma prática feita pelas mulheres ao longo dos séculos na imprensa, que resultou na escrita da história, do cotidiano e na escrita de si.

\section{Referências}

ARRUDA, Angela. Teoria das representações sociais e teorias de gênero. Caderno de Pesquisa. São Paulo, n. 117, p. 127-147, nov. 2002. Disponível em: http://dx.doi.org/10.1590/S0100-15742002000300007. Acesso em: 08 ago. 2019.

BARBOSA, Socorro de Fátima Pacífico. (Org.). Pequeno dicionário dos escritores jornalistas da Paraíba do século XIX. João Pessoa: Editora Universitária, 2009. Disponível em: http://www.cchla.ufpb.br/jornaisefolhetins/acervo/pequeno_d.pdf. Acesso em: 08 ago. 2018. 
BARBOSA FILHO, Hildeberto. Características da crônica paraibana. [Entrevista concedida a Maryellen Bãdãrãu]. João Pessoa, 18 jun. 2018.

BERNARDO, Ana Maria Coutinho. Gênero, história e educação na Paraíba: memórias de professoras e escritoras do início do século XX. João Pessoa: Universidade Federal da Paraíba, 2013. Disponível em: https://bit.ly/3gjxo11. Acesso em: 07 ago. 2018.

BUITONI, Dulcília. Helena Schroeder. Mulher de papel: a representação da mulher pela imprensa feminina brasileira. São Paulo: Edições Loyola, 1986.

CASADEI, Eliza Bachega. A inserção das mulheres no jornalismo e a imprensa alternativa: primeiras experiências do final do século XIX. Revista ALTERJOR: Jornalismo Popular e Alternativo. São Paulo, v.3, n.1, 3ed., jan.-jun. de 2011. Disponível em:

http://www.revistas.usp.br/alterjor/article/view/88218. Acesso em: 23 maio 2020.

CERTEAU, Michel de. A Escrita da história. Tradução de Maria de Lourdes Menezes. Revisão técnica [de] Arno Vogel. Rio de Janeiro: Forense Universitária, 1982.

DUARTE, Jorge; BARROS, Antônio (Org.). Métodos e técnicas de pesquisa em comunicação. São Paulo: Atlas, 2ed., 2006.

FERNANDES, Jéssica Luana; SILVA, Shirley Targino. Mulher, imprensa e educação na paraíba da década de 1930. In: CONGRESSO BRASILEIRO DE HISTÓRIA DA EDUCAÇÃO, 9., 2017, João Pessoa. Anais [...]. João Pessoa: UFPB, 2017. p. 1-2. Disponível em: https://bit.ly/2A4qYlW. Acesso em: 23 maio 2020.

FIGUEIRAS, R. As mulheres comentadoras na imprensa de referência portuguesa. Revista Alceu, Rio de Janeiro: PUC-RJ, v. 11, n.22, p. 74-89, jan.-jun. 2011. Disponível em: https://bit.ly/2ZxwVCv. Acesso em: 23 maio 2020.

GOMES, Angela de Castro (Org.). Escritas de si, escritas da história. Rio de Janeiro: Editora FGV, 2004.

GOTTARDI, Ana Maria. A crônica na mídia impressa. São Paulo: Arte \& Ciência, 2007.

JINZENJI, Mônica Yumi. Leitura e escrita femininas no século XIX. Cadernos Pagu, Campinas: Unicamp, n. 38, jan.-jun. de 2012. Disponível em: http://www.scielo.br/pdf/cpa/n38/n38a13.pdf. Acesso em: 23 maio 2020.

MAGALHÃES, Sara; ALVAREZ, Teresa (Org.). Mulheres e Media. Lisboa: Associação portuguesa de estudos sobre as mulheres, 2014.

MACHADO, Charliton José dos Santos. A Dimensão da Palavra: práticas de escrita de mulheres. João Pessoa: Editora Universitária/UFPB, 2005.

MATOS, Maria Zilda dos Santos de. História das mulheres e das relações de gênero: campo historiográfico, trajetórias e perspectivas. Revista Mandrágora, São Paulo, v.19. n.19, p. 5-15, 2013. Disponível em: https://bit.ly/2Xo2WdD. Acesso em: 23 maio 2020.

NASCIMENTO, Regina Coelli Gomes. Escrever/Inscrever-se: Práticas de (Re) criação de si nos escritos femininos na Paraíba na década de 1930. In: II Congresso Nacional de Educação, 2013, Campina Grande: UFCG. Anais. Disponível em: https://bit.ly/2X04qvm. Acesso em: 23 maio 2020. 
NUNES, Maria Lúcia da Silva; MACHADO, Charliton José dos Santos. Uma página Feminina: escritos para a educação das mulheres paraibanas (década de 1930). Revista HISTEDBR On-line, Campinas, v.1, n. 54, p. 189-206, dez. 2013. Disponível em: https://bit.ly/3giNCYa. Acesso em: 8 ago. 2018.

NUNES, Maria Lúcia. Quando as mulheres escrevem: Textos sobre a educação na imprensa paraibana. [Entrevista concedida ao Programa Espaço Experimental]. João Pessoa, 14 ago. 2016. Disponível em: https://bit.ly/2ZF0cem. Acesso em: 21 jul. 2018.

PAIVA, Kelen Benfenatti; DUARTE, Constância Lima. A mulher de letras: nos rastros de uma história. Revista Ipotesi, Juiz de Fora, v.13, n.2, p. 11-19, jul.-dez. 2009. Disponível em: https://bit.ly/2ZzyTSH. Acesso em: 23 maio 2020.

PEREIRA, Maria do Rosário Alves. A crônica feminina brasileira no século XIX. In: FAZENDO GêNERO: DIÁSPORAS, DIVERSIDADES E DESLOCAMENTOS, 9., 2010, Florianópolis. Anais [...]. Florianópolis: UFSC, 2010. p. 1-15. Disponível em: https://bit.ly/2zqvUS5. Acesso em: 23 maio 2020.

PEREIRA, Wellington. A Comunicação e a cultura no cotidiano. Revista FAMECOS, Porto Alegre, v.14, n.32, p. 66-70, abr. 2007. Disponível em: https://bit.ly/2ZK1k0H. Acesso em: 23 maio 2020.

PEREIRA, Wellington. Crônica: Arte do útil ou do fútil? Ensaio sobre a crônica no jornalismo impresso. João Pessoa: Idéia, 1994.

PINHEIRO, Alexandra Santos. Leitoras e interlocutoras da literatura oitocentista: literatura e gênero no Jornal das Famílias (1863-1878). São Paulo: Edigal, 2010.

SALES, Ana Maria Coutinho. Tecendo fios de liberdade: Escritoras e professoras da Paraíba do começo do Século XX. Tese de doutorado. UFPE: Recife, 2005. Disponível em: https://bit.ly/2TzEViy. Acesso em: 23 maio 2020.

SOUZA, Thiago Oliveira de; CURY, Cláudia Engler. Considerações sobre a instrução na imprensa paraibana oitocentista (1849-1889). In: SIMPÓSIO NACIONAL DE HISTÓRIA, 26. 2011, São Paulo. Anais [...]. São Paulo: Anpuh, 2011. Disponível em: https://bit.ly/2TztgAl. Acesso em: 22 maio 2020.

TELES, Amelinha. LEITE, Rosalina Santa Cruz. Da Guerilha à Imprensa: A construção do feminismo pós-luta armada no Brasil (1975-1980). São Paulo: Intermeios, 2013.

TEDESCHI, Losandro Antonio. Os desafios da escrita feminina na história das mulheres. Revista Raído, Dourados: v.10, n.21, p. 153-164, jan.-jun. 2016. Disponível em: ojs.ufgd.edu.br/index.php/Raido/article/download/5217/2737. Acesso em: 29 out. 2018.

VILAR, Socorro de Fátima Pacífico. O conceito de literatura nos periódicos e jornais do século XIX: um estudo dos jornais paraibanos: um estudo dos jornais paraibanos. In: ENCONTRO REGIONAL DA ABRALIC, 10., 2005, Rio de Janeiro. Anais [...]. Rio de Janeiro: ABRALIC, 2005. Disponível em: https://bit.ly/3ecPcZS. Acesso em: 17 jul. 2018. 